\title{
Morphological Mutants of Escherichia coli. Isolation and Ultrastructure of a Chain-forming envC Mutant
}

\author{
By ANNIE RODOLAKIS, P. THOMAS AND J. STARKA \\ Laboratoire de Chimie Bactérienne, C.N.R.S., Laboratoire de Cytologie Végétale and \\ Laboratoire de Physiologie Microbienne, Centre Universitaire de Marseille-Luminy, \\ I3009 Marseille, France
}

(Received I5 November 1972)

\begin{abstract}
Non-conditional morphological mutant envC derived from Escherichia coli K-I 2 strain $\mathrm{P} 678$, isolated after treatment with I-methyl-3-nitro-I-nitrosoguanidine, produced chains of bacteria on synthetic or rich media at $30^{\circ} \mathrm{C}$ and $40^{\circ} \mathrm{C}$. It was sensitive to deoxycholate and less resistant to penicillin and rifampicin than the parent strain. In section under the electron microscope, the mutant showed greatly disorganized septum formation. Preliminary mapping of envC by conjugation located it near $x y l$. The morphological and physiological characteristics of env $C^{+}$ recombinants and the $e n v C^{+}$parent were identical.
\end{abstract}

\section{INTRODUCTION}

The mechanisms that control bacterial morphology and division are not clearly understood. Most mutations affecting these processes might be expected to be lethal. However, recent reports show that conditional and non-conditional morphological mutants can be obtained and used to learn something about their physiology and genetics. In their extensive study of thermosensitive mutants of Escherichia coli K-12, Kohiyama, Cousin, Ryter \& Jacob (I966) observed many strains which grew normally at permissive temperatures but presented morphological, cytological and physiological alterations and irregularities in division at $40^{\circ} \mathrm{C}$. Three principal types of alterations were recognized: (i) filament and chain formation, (ii) irregular morphology; and (iii) spherical forms. Several other authors isolated non-conditional or thermosensitive mutants of $E$. coli with characteristic morphological alterations belonging to one of these groups (Normark, Boman \& Matsson, I962; Adler, Terry \& Hardigree, I968; Hirota, Ricard \& Shapiro, 197x; Henning et al. 1972; Lazdunski \& Shapiro, 1972). Another type of conditional mutant of $E$. coli is osmotically unstable at non-permissive temperature and the bacteria lyse (Kohiyama et al. 1966; Mangiarotti, Apirion \& Schlessinger, I966; Matsuzawa, Matsuhashi, Oka \& Sugino, I 969). In most cases lysis can be prevented by osmotic stabilization.

Morphological mutants and mutants defective in peptidoglycan synthesis were also reported for Bacillus subtilis, B. licheniformis, Staphylococcus aureus and Agrobacterium tumefaciens (Rogers, McConnell \& Burdett, 1968; Boylan \& Mendelson, 1969; Chatterjee \& Young, 1972; Fujiwara \& Fukui, 1972; Good \& Tipper, 1972). It appears that the morphological defect is generally accompanied by a chemical and/or structural alteration of wall or cytoplasmic membrane and that the division is also affected in most cases.

During our recent work with morphological mutants we have isolated a chain-forming mutant of Escherichia coli K-I 2 which is not thermosensitive. In this first communication we 


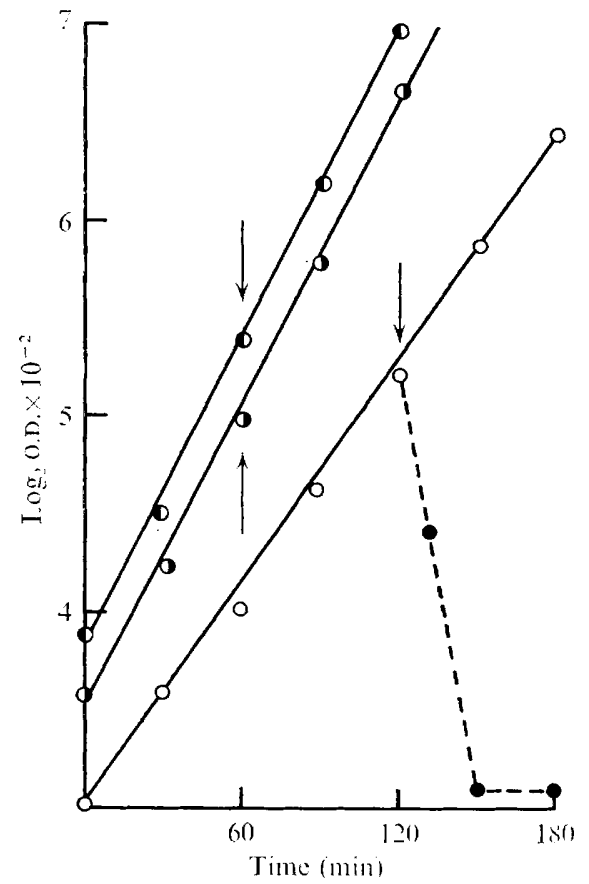

Fig. I. Growth of the mutant PM6I $(O)$, of the parent strain P678 $(O)$ and of the recombinant PM6I $\times$ P4X (O). DOC (0.I\% final concn) added to P678 and to the recombinant (arrows) was without effect on growth rate, but produced a rapid lysis $(\bullet)$ of PM6r. Temperature, $37^{\circ} \mathrm{C}$.

describe the ultrastructural characteristics of the defective division and some physiological properties of this mutant. The gene mutated, designated envC, maps in the xylose $(x y l)$ region of bacterial chromosome.

\section{METHODS}

Strain. The strain Escherichia coli K-1 2 P678 originally isolated by F. Jacob was obtained from $\mathrm{H}$. I. Adler and has the following genetic constitution: $\mathrm{F}^{-}$thr leu lac gal xyl mal man thi and is resistant to streptomycin.

Mutant isolation. To obtain both thermosensitive and non-conditional mutants, organisms of the strain $\mathrm{P} 678$ grown in rich medium were mutagenized with I-methyl-3-nitro-I-nitrosoguanidine (Kohiyama et al. 1966). After mutagenesis bacteria were washed free of mutagen, allowed to grow overnight in rich medium at $30^{\circ} \mathrm{C}$ and then plated on solid medium. The colonies were replicated twice on the same medium and incubated at $30^{\circ} \mathrm{C}$ and $40^{\circ} \mathrm{C}$, respectively. Selection of morphological mutantswas made by observation of organisms in each colony under a phase contrast microscope. Strain PM6I was one of a number of mutants purified from colonies which grew more slowly after replication and were visible only after $48 \mathrm{~h}$ incubation at both temperatures.

Media and growth. Rich medium contained (g/l distilled water): Bacto peptone (Difco, Detroit, Michigan, U.S.A.), 5; Bacto beef extract (Difco), 3; Bacto yeast extract (Difco), 3; $\mathrm{NaCl}, 5$. Rich medium for colony growth and replica plating was made by solidifying this medium with $12 \mathrm{~g}$ Bacto agar/l. Tryptose medium contained (g/l distilled water): Bacto tryptose (Difco), 5; NaCl, ro. Tris-buffered synthetic medium was that of Hershey (I955), 

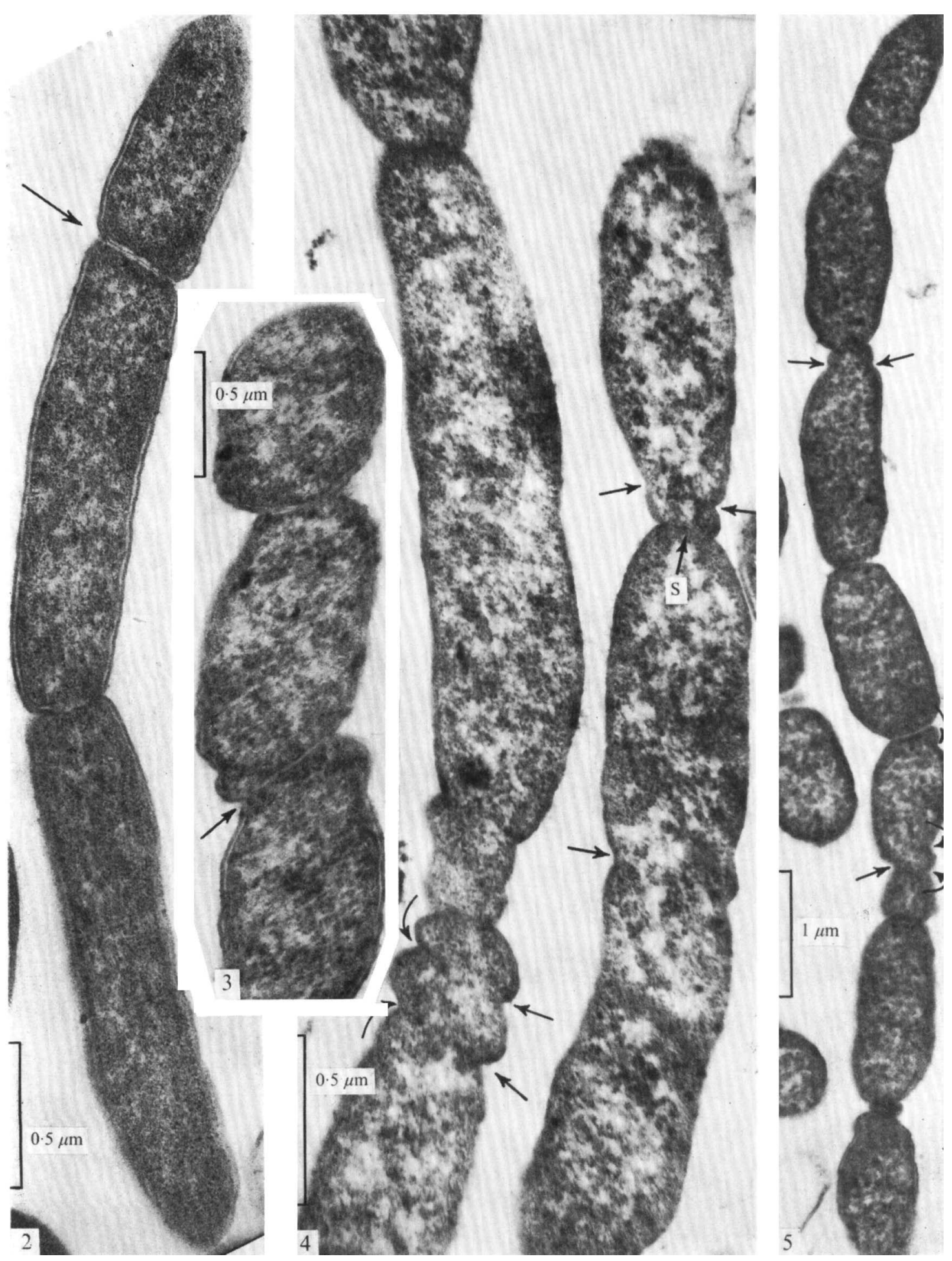

Fig. 2. A section through a part of a chain of PM61, showing arrangement of septum (arrow) enlarged on Fig. 7.

Fig. 3. Oblique septum and infoldings of the wall.

Fig. 4. Anomalous wall constrictions often without achieved septum (arrows). S, septum.

Fig. 5. Chain of bacteria mostly with achieved septa. Arrows indicate 'abortive' constrictions. 

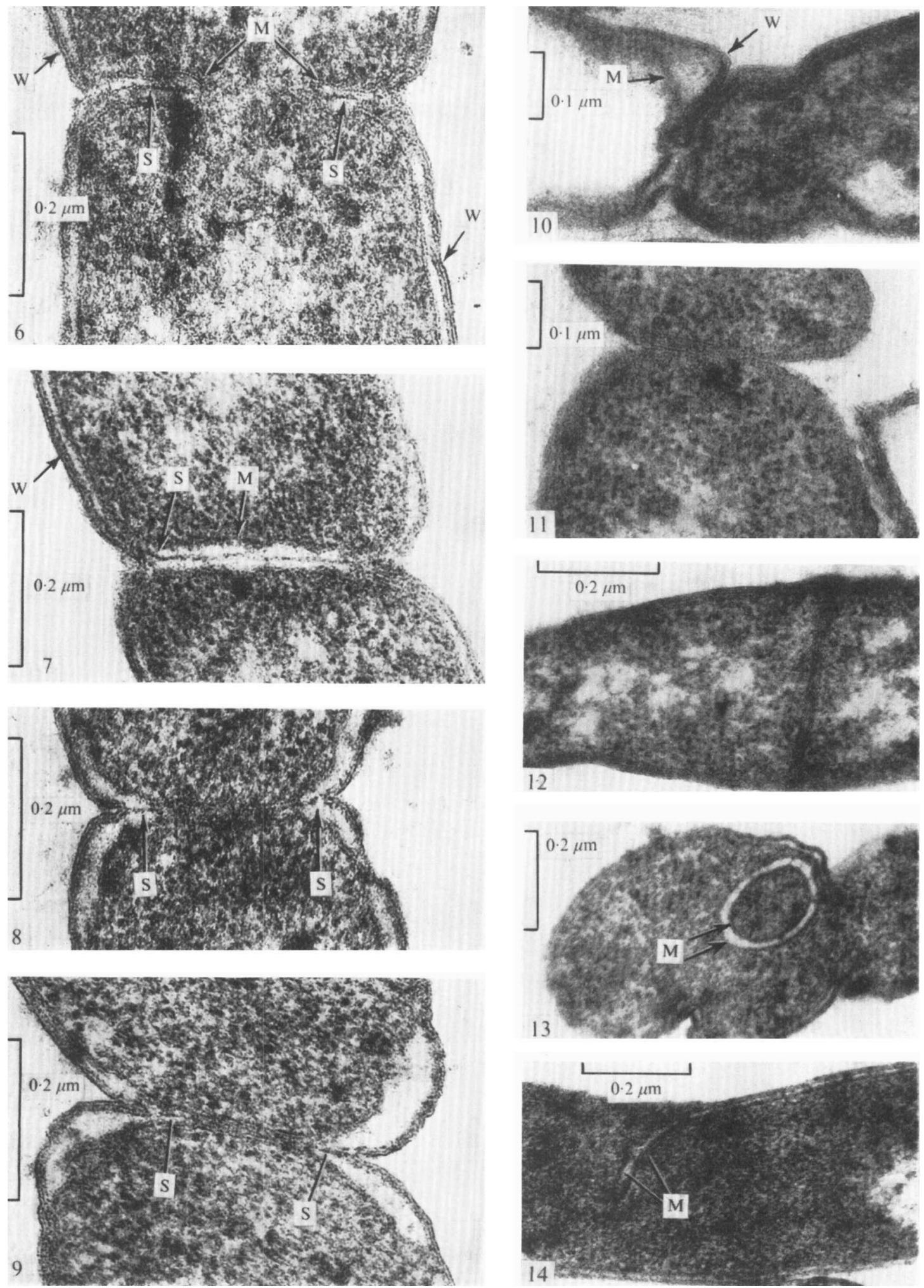
supplemented with thiamine, threonine and leucine of $50 \mu \mathrm{g} / \mathrm{ml}$. Growth of agitated cultures was measured in a Jean \& Constant spectrophotometer at $450 \mathrm{~nm}$.

Electron microscopy. Cultures on rich medium were centrifuged and fixed by glutaraldehyde and osmium tetroxide according to Ryter \& Jacob (1966). Ultrathin sections of bacteria embedded in Araldite were contrasted with potassium permanganate (Thomas, 1972).

Bacterial matings. Conjugation experiments were performed at $37^{\circ} \mathrm{C}$ in rich medium using Hfr P4X met thi $(\lambda)^{+}$sensitive to streptomycin, as donor. Mating mixtures of exponentially growing bacteria containing about $5 \times 10^{6} \mathrm{Hfr}$ and $10^{8} \mathrm{~F}^{-}$organisms $/ \mathrm{ml}$ were incubated for $90 \mathrm{~min}$ and appropriate dilutions were plated on selective media.

\section{RESULTS}

\section{General characteristics of the chain-forming mutant $\mathrm{PM} 6 \mathrm{I}$}

Mutant PM6I, observed stained or unstained under phase contrast after growth on liquid rich medium at $47^{\circ} \mathrm{C}$, formed long chains consisting of individuals of rather irregular length between I and $10 \mu \mathrm{m}$; their number ranged from 10 to 80 and more per chain. In the minimal medium the chains were generally shorter. Culture at $30^{\circ} \mathrm{C}$ or $40^{\circ} \mathrm{C}$ did not affect the morphology. The generation time in tryptose medium at $37^{\circ} \mathrm{C}$ was $53 \mathrm{~min}$ for PM6I and 36 min for the parental strain P678. A striking difference between the mutant and the parent was observed when sodium deoxycholate (DOC) was added to growing cultures of both strains: the parental strain grew normally with I \% DOC but growth of PM6I was inhibited by $0.1 \%$ detergent (Fig. I). In tryptose medium, PM6I was inhibited to $10 \mu \mathrm{g}$ penicillin $/ \mathrm{ml}$ and by $0.5 \mu \mathrm{g}$ rifampicin $/ \mathrm{ml}$; for $\mathrm{P} 678$, inhibitory concentrations were $50 \mu \mathrm{g}$ penicillin $/ \mathrm{ml}$ and $10 \mu \mathrm{g}$ rifampicin $/ \mathrm{ml}$.

\section{Electron microscopic observations}

Thin sections in the electron microscope indicated that septum formation by PM6I was either accompanied (Fig. 2) or not (Fig. 12) by a constriction of the dividing organism. The portion of the cytoplasmic membrane invaginating at the division plane formed a simple fold, progressively separating the daughters (Fig. 6, 7, 8). The invagination of the membrane was followed by formation of a thin septum connected with the dark layer surrounded by the outer membrane (Fig. 9). This layer is considered to be the mucopeptide containing portion of the wall (De Petris, 1965; 1967).

In most cases the constriction of the outer membrane stopped at an early stage, presumably because the mucopeptide layer could not be split in two separate structures. In stationary phase of the growth some individuals were lysed but they were still attached to the

Fig. 6. Early stage of the division. Invaginated cytoplasmic membrane (M) surrounds a monolayered septum (S) growing out of the internal (mucopeptide) layer of the wall (W).

Fig. 7 to 9. Two daughter organisms completely separated by a septum. Arrows indicate a fork-like attachment of the central layer of the septum (S) to the internal layer of the wall. This is the stage of division most frequently found in sections of chains. $\mathbf{M}$, cytoplasmic membrane.

Fig. 10. A section of an autolysed organism with invaginated wall (W) including outer membrane. $\mathrm{M}$, cytoplasmic membrane.

Fig. I I. Advanced stage of division showing completed septum with outer membrane.

Fig. 12. Septum without typical constriction.

Fig. 13. Vesicular invagination of cytoplasmic membrane. Note the sparse layer between two membranes (M).

Fig. 14. Oblique invagination of cytoplasmic membrane (M). 
Table I. Anlayses for unselected markers in selected recombinants from a cross between $\mathrm{P} 4 \mathrm{X}$ and $\mathrm{PM} 6 \mathrm{I}$

$\begin{array}{lccccc}\begin{array}{c}\text { Selected } \\ \text { recombinants }\end{array} & \begin{array}{c}\text { Number } \\ \text { tested }\end{array} & \mathrm{Thr}^{+} \mathrm{Leu}^{+} & \mathrm{Xyl^{+ }} & \mathrm{Mal}^{+} & \mathrm{enC}^{-} \\ t h \mathrm{r}^{+} \mathrm{leu}^{+} & \mathrm{I} 53 & - & 25 & 5 & 38 \\ \mathrm{xy} \mathrm{l}^{+} & \mathrm{I} 6 & 29 & - & 26 & 90\end{array}$

The symbol env $C^{+}$designates recombinants having normal morphology.

Streptomycin was used as a contraselector.

chain by uncompleted septa (Fig. Io). A complete septum was found only exceptionally (Fig. II).

Another interesting phenomenon occurring rather frequently was the presence of several constrictions of the envelope in the proximity of incomplete septa, as if there were several unsuccessful attempts at division (Fig. 4, 5). These constrictions were sometimes asymetrical or only on one side of the organism (Fig. 3). In some, the cytoplasmic membrane formed intracytoplasmic invaginations (Fig. I3, I4), but these structures could be seen only occasionally.

It seems that the phenotypic expression of this mutation concerns septum formation and the organization of the envelope. Thus our mutant PM6r appears to belong to the group of env mutants described by Normark et al. (I969).

\section{Genetic localization of the env C locus}

The envA mutation-mediating chain formation in the strain D22 of Escherichia coli is located between $l e u$ and $a z i$ at $\mathbf{I} \cdot 5 \mathrm{~min}$ (Normark, I970). Another mutant producing irregular sphere-like organisms was designated $e n v B$ by the same author and it maps near streptomycin resistance. Since the physiological and cytological properties of PM6I are closely similar to D22 (envA), it was important to locate the env mutation-mediating chain formation of our strain.

We performed a number of mating experiments with Hfr P4x (Wollman strain, met thi $\left.(\lambda)^{+}\right)$which transfers in the order pro-leu-thr-xyl-mal-str. All selected recombinant were observed microscopically. An analysis of the various recombinants obtained in one cross is shown in Table I. Conjugation experiments indicate a strong linkage $(90 \%)$ between envC and $x y l$; thus the mutated gene appears to be located in $x y l$ region and to be distinct from $e n v A$. It is not identical with envB whose phenotypic expression (amorphous organisms) and chromosomal location near str are different. Therefore we designate the mutation of PM6I as $e n v C$. A more detailed mapping of envC by transduction is in progress.

The one $e n v C^{+} x y l^{+}$mal gal lac met man man thi str-r recombinant tested was resistant to DOC and less sensitive to penicillin and rifampicin than PM6I. Its growth rate was exactly the same as that of the parental strain P678 (Fig. I).

\section{DISCUSSION}

Genetically determined morphological changes in bacteria have been observed mainly with conditional mutants. This is not surprising, since most non-conditional mutations affecting production or activity of wall-synthesizing enzymes, or other processes involved in division or leading to unbalanced formation of wall or cytoplasmic membrane, are expected 
to be lethal. The few non-conditional mutants of Escherichia coli of which we are aware belong to two morphological types: (i) irregular sphere-like organisms of mon mutant (Adler et al. 1968) and of envB mutant (Normark, 1969); and (ii) chain-forming mutants env $A$ (Normark et al. 1969) and envC described in the present paper.

The mutants mon and $e n v B$ are similar in several respects, as pointed out by Normark (I969). The envB gene maps near streptomycin resistance and preliminary experiments performed in our laboratory (L. A. Genta, unpublished), indicate that the mon gene is also located in this region.

Although env $A$ and $e n v C$ mutants are phenotypically similar, our conjugation experiments indicate that envC is not identical with env $A$. A more detailed comparison of these mutants is necessary.

The alteration of shape of a number of Escherichia coli mutants appears to be a phenotypic expression of mutations in several different genes mon, rod, env, but in no case has the primary effect of the mutation been identified. It is not clear whether the morphology is determined by the cytoplasmic membrane or by some other structure of the envelope. Although the role of the cytoplasmic membrane seems to be of special importance (Henning et al. 1972; Ingram, Van Baalen \& Fisher, 1972), the role of the remaining layers cannot be eliminated.

This work was supported by a grant from la Délégation Générale à la Recherche Scientifique et Technique and L'Institut National de la Santé et de la Recherche Médicale.

\section{REFERENCES}

Adler, H. I., Terry, C. E. \& Hardigree, A. A. (1968). Giant cells of Escherichia coli. Journal of Bacteriology 95, $139-142$.

Boylan, R. J. \& MENDElson, N. H. (1969). Initial characterization of a temperature-sensitive rod mutant of $^{-}$ Bacillus subtilis. Journal of Bacteriology 100, $1316-1321$.

Chatterjee, A. N. \& Young, F. E. (1972). Regulation of the bacterial cell wall: Isolation and characterization of peptidoglycan mutants of Staphylococcus aureus. Journal of Bacteriology II r, 220-230.

DE PETRIS, S. (1965). Ultrastructure of the cell wall of Escherichia coli. Journal of Ultrastructure Research I2, 247-262.

De Petris, S. (1967). Ultrastructure of the cell wall of Escherichia coli and chemical nature of its constituent layers. Journal of Ultrastructure Research $\mathbf{1 9}, 45-83$.

Fujiwara, T. \& Fukui, S. (1972). Isolation of morphological mutants of Agrobacterium tumefaciens. Journal of Bacteriology I10, 743-746.

Good, C. M. \& TIPPER, D. J. (1972). Conditional mutants of Staphylococcus aureus defective in cell wall precursor synthesis. Journal of Bacteriology II I, 23I-24I.

Henning, V., Rehn, K., Braun, V., Höhn, B. \& Schwarz, U. (1972). Cell envelope and shape of Escherichia coli K12. Properties of a temperature-sensitive rod mutant. European Journal of Biochemistry 26, $570-586$.

Hershey, A. D. (1955). An upper limit to the protein content of the germinal substance of bacteriophage $\mathrm{T} 2$. Virology, $\mathbf{1}, \mathrm{I} 08$.

Hirota, Y., Ricard, M. \& Shapiro, B. (1971). The use of thermosensitive mutants of E. coli in the analysis of cell divison. In Biomembranes, vol. 2, pp. 13-3I. Edited by L. A. Manson. New York and London: Plenum Press.

INGRAM, L. O., VAN BAALEN, C. \& Fisher, W. D. (1972). Cell division mutations in the blue-green bacterium Agmenellum quadruplicatum strain BGI: A comparison of the cell wall. Journal of Bacteriology IrI, $614-621$.

Kohiyama, M., Cousin, D., Ryter, A. \& Jacob, F. (1966). Mutants thermosensibles d'Escherichia coli K 12. I. Isolement et caractérisation rapide. Annales de l'Institut Pasteur 1 1o, 465-486.

LAZDUNSKI, C. \& SHAPIRO, B. M. (1972). Isolation and some properties of cell envelope altered mutants of Escherichia coli. Journal of Bacteriology $1 \mathrm{I}$, 495-498.

Mangiarotti, G., Apirion, D. \& Schlessinger, D. (1966). Selection of sucrose-dependent Escherichia coli to obtain envelope mutants and fragile cultures. Science, New York 153, 892-894. 
Matsuzawa, H., Matsuhashi, M., OKa, A. \& Sugino, Y. (1969). Genetic and b iochemical studies on cel wall peptidoglycan synthesis in Escherichia coli K-12. Biochemical and Biophysical Research Communications 36, 682-689.

Normark, S. (1969). Mutation in Escherichia coli K-I 2 mediating spherelike envelopes and changed tolerance to ultraviolet irradiation and some antibiotics. Journal of Bacteriology 98, 1274-I 277.

Normark, S. (1970). Genetics of a chain-forming mutant of Escherichia coli. Transduction and dominance of the envA gene mediating increased penetration to some antibacterial agents. Genetical Research $\mathbf{1 6}$, $63-78$.

Normark, S., Boman, H. G. \& Matsson, E. (1969). Mutant of Escherichia coli with anomalous cell division and ability to decrease episomally and chromosomally mediated resistance to ampicillin and several other antibiotics. Journal of Bacteriology 97, I334-1342.

Rogers, H. J., McConnell, M. \& Burdett, I. D. J. (I968). Cell wall or membrane mutants of Bacillus subtilis and Bacillus licheniformis with grossly deformed morphology. Nature, London 219, 285-288.

RYTER, A. \& JACOB, F. (1966). Étude morphologique de la liaison du noyau à la membrane chez Escherichia coli et chez les protoplastes de Bacillus subtilis. Annales de l'Institut Pasteur Iro, 801-8I2.

Thomas, P. (1972). Ultrastructure de Desulfovibrio gigas Le Gall et de Desulfovibrio hildenborough. Journal de Microscopie $\mathbf{3}, 349-360$. 